\title{
Prevalence urinary tract infections in newborns of Baghdad
}

\section{hospital}

\author{
By

\section{Dr. Mazin Imad Ahmed ${ }^{* 1}$; Assist prof. Dr. Nihad Khalawe Tektook ${ }^{* 2}$; Dr. Rahan Assim Mohammed Al-Qazzaz ${ }^{* 3}$} \\ ${ }^{* 1}$ Specialist in Neonatal intensive care unit, F.I.B.M.S pediatrics, Al-Elwiya Maternity teaching \\ hospital, Baghdad- Alrusafa/Health Directorate, Ministry of Health and Environment, Baghdad, Iraq; \\ ${ }^{* 2}$ Middle Technical University / College of Medical \&Health Technology, Medical laboratory \\ techniques dep. Iraq; ${ }^{* 3}$ Pediatrics specialist ,CABMS pediatrics Al-Sheikhan General Hospital,
} Nineveh , Ministry of Health and Environment, iraq.

\begin{abstract}
In the neonatal period, urinary tract infection sepsis and urinary system It is an important clinical problem because it can be associated with congenital anomalies. The aim was determine the prevalence of UTI and the causative agent in neonates with their antibiotics sensitivity patterns. This study was planned as cross-sectional study. urinary tract at a 4-year time interval in a primary neonatal unit. It was performed on newborns who were hospitalized with the diagnosis of infection. patient data It was obtained retrospectively from patient files. Prior hospitalization, urinary catheterization, premature birth and urinary Newborns with multipathogen growth in their culture were not included in the study. for study Consent was obtained from the local ethics committee. Urinary tract infection, urine sample taken by bladder catheterization $10000-50000 \mathrm{CFU} / \mathrm{ml}$ colony count or pyuria in the presence of pyuria in the culture Colony count of $\geq 50000 \mathrm{CFU} / \mathrm{ml}$ in the absence of microorganism was defined as growth. Gender of the patients, weeks of gestation, mode of delivery, birth weight, urinary tract postnatal days of diagnosis of infection. The difference and relationships between the obtained data were statistically evaluated. In the present study, 186 urine specimens from neonates with UTI, 110(59.13\%) were positive for bacterial culture. In addition 100 specimens from healthy neonates (control) included in the present study, only $8(8 \%)$ were positive for bacterial culture The study showed that, E. coli were the most isolated bacteria According to the distribution of the isolated bacteria among the study groups, $K$. pneumoniae is the second, $S$. aureus and $P$. mirabilis the least isolated bacteria from neonates, The study showed that majority of neonates with UTI were females $(65.45 \%)$ and $34.55 \%$ were males, The study demonstrated that, most cases suffered from dysuria due to UTI and $27.27 \%$ suffered from fever, The research indicated that, S. aureus showed high rate of sensitivity to ciprofloxacin and oxacillin $(88.23 \%)$ and resistant to ampicillin and lincomycin. S. saprophyticus showed were sensitive to cephalothin, ciprofloxacin, oxacillin and lincomycin and complete resistant to ampicillin, erythromycin and amikacin. Streptococcus faecalis showed $100 \%$ sensitivity to oxacillin while it was resistant to ciprofloxacin, ampicillin, erythromycin and amikacin. E. coli isoaltes were
\end{abstract}


sensitive to to ceftazidim and resistant to oxacillin and lincomycin . K. pneumoniae were sensitive to amoxiclave and resistant to ampicillin, tetracycline, erythromycin, oxacillin and lincomycin. Proteus mirabilis was sensitive to cefotaxim and it was resistant to erythromycin, ampicillin, oxacillin and lincomycin. Proteus vulgaris showed high sensitivity rate to nirtrofurontoin, cefotaxim (92.85\%) and low rate of sensitivity to erythromycin (Figure 4.8). Pseudomonas aeroginosae showed high sensitivity rate to cefotaxim $(86.66 \%)$ and low rate of sensitivity $(20 \%)$ to ampicillin.

Keywords: UTI; Neonates; Urine culture; E. coli; Baghdad hospital

\section{Introduction}

In the neonatal period, urinary tract infection sepsis and urinary system It is an important clinical problem because it can be associated with congenital anomalies. Urinary tract infection in term newborns admitted to the hospital with fever While the frequency is about $15 \%$, it can reach $25 \%$ in babies weighing less than 1500 grams. 2 The diagnosis of urinary tract infection in term infants is often postnatal 2.3-3. Frequency of urinary tract infection in early neonatal sepsis It is below $2 \% .3$ Urinary tract infections in term newborns are quite large, as $80 \%$. Escherichia coli (E. coli) is responsible for the part. However, Klebsiella, Proteus, Other gram-negative bacteria such as Enterobacter and Citrobacter, and Enterococcus and rarely gram-positive bacteria such as Staphylococcus aureus are microorganisms.4 In premature newborns hospitalized, Klebsiella and coagulase-negative Staphylococcus species are frequently detected as the causative agent. Candida types are an important urinary tract for premature babies weighing less than 1000 grams. is the causative agent of infection.5 Urinary tract infections in male infants and especially in uncircumcised male infants. The risk of infection is considerably higher than for female babies. urinary tract in the first trimester approximately $75 \%$ of cases of infection are male infants.1,6 Neonatal urinary tract infection in 
terms of its association with congenital renal and urinary system anomalies. is important. Pelviectasis and mild hydronephrosis are the most common anomalies. $5-10 \%$ of patients have high-grade hydronephrosis, vesicoureteral reflux, and significant there are structural anomalies.7,8 The aim was determine the prevalence of UTI and the causative agent in neonates with their antibiotics sensitivity patterns.

\section{Material and Method}

This study was planned as cross-sectional study. urinary tract at a 4-year time interval in a primary neonatal unit. It was performed on newborns who were hospitalized with the diagnosis of infection. patient data It was obtained retrospectively from patient files. Prior hospitalization, urinary catheterization, premature birth and urinary Newborns with multipathogen growth in their culture were not included in the study. for study Consent was obtained from the local ethics committee. Urinary tract infection, urine sample taken by bladder catheterization 10000-50000 CFU/ml colony count or pyuria in the presence of pyuria in the culture Colony count of $\geq 50000 \mathrm{CFU} / \mathrm{ml}$ in the absence of microorganism was defined as growth. Gender of the patients, weeks of gestation, mode of delivery, birth weight, urinary tract postnatal days of diagnosis of infection, admission complaints, physical presence of fever and phimosis for male patients, complete urine density and $\mathrm{pH}$ values, pyuria and nitrite positivity, urine types of microorganisms grown in their cultures and antibiogram results, blood culture results were recorded. The difference and relationships between the obtained data were statistically evaluated.

\section{Results}

In the present study, 186 urine specimens from neonates with UTI, $110(59.13 \%)$ were positive for bacterial culture. In addition 100 specimens from 
healthy neonates (control) included in the present study, only $8(8 \%)$ were positive for bacterial culture as summarized in Table 1.

Table 1: Results of urine culture among study groups.

\begin{tabular}{|c|c|c|c|c|}
\hline \multirow{2}{*}{$\begin{array}{c}\text { Results of urine } \\
\text { culture }\end{array}$} & \multicolumn{2}{|c|}{ Neonates with UTI } & \multicolumn{2}{c|}{ (Control) } \\
\cline { 2 - 5 } & No. & $\%$ & No. & $\%$ \\
\hline $\begin{array}{c}\text { Positive Bacterial } \\
\text { culture }\end{array}$ & 110 & 59.13 & 8 & 8 \\
\hline $\begin{array}{c}\text { Negative Bacterial } \\
\text { Culture }\end{array}$ & 76 & 40.86 & 92 & 92 \\
\hline Total & 186 & 100 & 100 & 100 \\
\hline
\end{tabular}

In the present study. 32(29.09\%) were Gram positive bacteria, while 78(70.9\%) specimens were Gram negative bacteria. Among 8 specimens from unmarried healthy women (control ) included in the present study, only 3 $(37.5 \%)$ isolates were $\mathrm{G}+\mathrm{ve}$ isoaltes, while 5 (62.5\%) isolates were Gram negative bacteria as summarized in Table 2.

Table 2: Types of isolated bacteria among study groups.

\begin{tabular}{|c|c|c|c|c|}
\hline \multirow{2}{*}{ Results of urine culture } & \multicolumn{2}{|c|}{ Neonates with UTI } & \multicolumn{2}{c|}{ (Control) } \\
\cline { 2 - 5 } & No. & $\%$ & No. & $\%$ \\
\hline G+ve & 32 & 29.09 & 3 & 37.5 \\
\hline G-ve & 78 & 70.9 & 5 & 62.5 \\
\hline Total & 110 & 100 & 8 & 100 \\
\hline
\end{tabular}

The study showed that, E. coli were the most isolated bacteria According to the distribution of the isolated bacteria among the study groups, $K$. pneumoniae is the second, $S$. aureus and $P$. mirabilis the least isolated bacteria from neonates, Figure 1. 


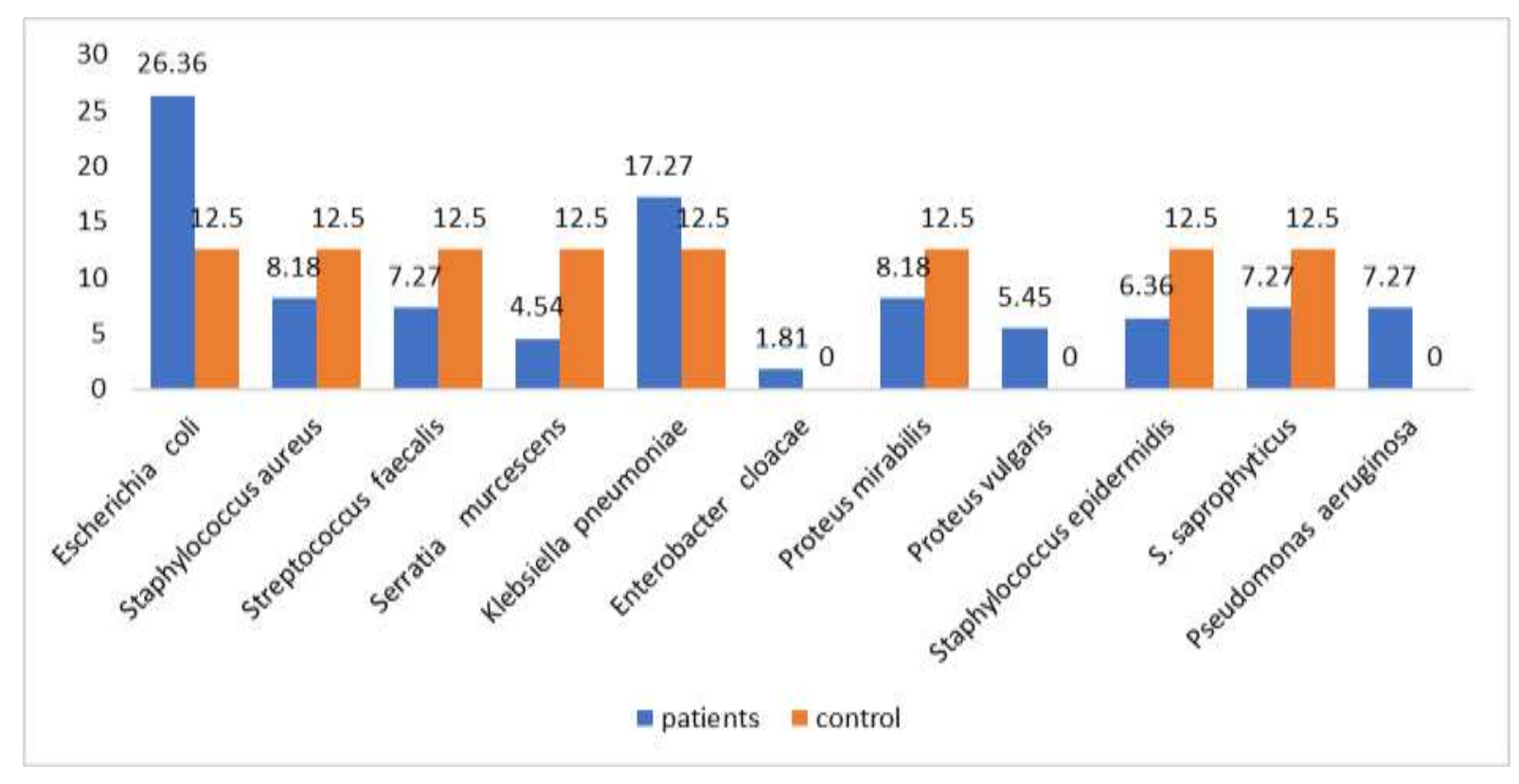

Figure 1: Distribution of isolated bacteria among study groups.

The study showed that majority of neonates with UTI were females $(65.45 \%)$ and $34.55 \%$ were males, Table 3.

Table 3: Distribution of UTI according to sex of patients

\begin{tabular}{|c|c|c|c|c|}
\hline \multirow{2}{*}{ Sex } & \multicolumn{2}{|c|}{ Positive UTI } & \multicolumn{2}{c|}{ Negative UTI } \\
\cline { 2 - 5 } & No. & $\%$ & No. & $\%$ \\
\hline Males & 38 & 34.55 & 33 & 43.42 \\
\hline Females & 72 & 65.45 & 43 & 56.58 \\
\hline Total & 110 & 100 & 76 & 100 \\
\hline
\end{tabular}

The study demonstrated that, most cases suffered from dysuria due to UTI and $27.27 \%$ suffered from fever, Table 4.

Table 4: Distribution of clinical feature UTI

\begin{tabular}{|l|l|l|}
\hline Clinical Feature & \multicolumn{2}{|l|}{ Positive UTI Cases (110) } \\
\cline { 2 - 3 } & No. & $\%$ \\
\hline
\end{tabular}




\begin{tabular}{|l|l|l|}
\hline Fever & 30 & 27.27 \\
\hline Dysuria & 80 & 72.73 \\
\hline
\end{tabular}

The research indicated that, $S$. aureus showed high rate of sensitivity to ciprofloxacin and oxacillin (88.23\%) and resistant to ampicillin and lincomycin. S. saprophyticus showed were sensitive to cephalothin, ciprofloxacin, oxacillin and lincomycin and complete resistant to ampicillin, erythromycin and amikacin. Streptococcus faecalis showed $100 \%$ sensitivity to oxacillin while it was resistant to ciprofloxacin, ampicillin, erythromycin and amikacin. Table 5 
Table 5: Antibiotic sensitivity patterns of G+ve isolates

\begin{tabular}{|c|c|c|c|c|}
\hline \multirow[t]{2}{*}{ Type of antibiotic } & \multicolumn{4}{|c|}{ Bacteria } \\
\hline & $\begin{array}{l}\text { S. aureus } \\
(\%)\end{array}$ & $\begin{array}{c}\text { S. Epidermidis } \\
(\%)\end{array}$ & $\begin{array}{c}\text { S. saprophyticus } \\
(\%)\end{array}$ & E. faecalis $(\%)$ \\
\hline Ciprofloxacin & 88.23 & 50 & 56.25 & 0 \\
\hline Ampicillin & 0 & 0 & 0 & 0 \\
\hline Tetracycline & 47.05 & 28.57 & 43.75 & 30 \\
\hline Erythromycin & 70.58 & 50 & 0 & 0 \\
\hline Tobramycin & 82.35 & 92.85 & 50 & 50 \\
\hline Gentamicin & 82.35 & 85.71 & 50 & 10 \\
\hline Oxacillin & 88.23 & 92.85 & 56.25 & 100 \\
\hline Penicillin G & 5.88 & 0 & 12.5 & 20 \\
\hline Streptomycin & 70.58 & 57.14 & 50 & 20 \\
\hline Chloramphenicol & 58.82 & 50 & 6.25 & 30 \\
\hline Trimethoprim & 70.58 & 50 & 50 & 30 \\
\hline Clindamycin & 58.82 & 57.14 & 50 & 30 \\
\hline Lincomycin & 0 & 0 & 56.25 & 30 \\
\hline Ceftazidim & 58.82 & 50 & 43.75 & 50 \\
\hline Amoxicillin & 11.76 & 0 & 37.5 & 50 \\
\hline Cephalothin & 58.82 & 85.71 & 75 & 60 \\
\hline Amikacin & 47.05 & 71.42 & 0 & 0 \\
\hline Amoxiclave & 47.05 & 50 & 50 & 60 \\
\hline Nitrofurantoin & 47.05 & 64.28 & 50 & 80 \\
\hline Cefotaxime & 41.17 & 71.42 & 50 & 40 \\
\hline
\end{tabular}


E. coli isoaltes were sensitive to to ceftazidim and resistant to oxacillin and lincomycin . K. pneumoniae were sensitive to amoxiclave and resistant to ampicillin, tetracycline, erythromycin, oxacillin and lincomycin. Proteus mirabilis was sensitive to cefotaxim and it was resistant to erythromycin, ampicillin, oxacillin and lincomycin. Proteus vulgaris showed high sensitivity rate to nirtrofurontoin, cefotaxim $(92.85 \%)$ and low rate of sensitivity to erythromycin (Figure 4.8). Pseudomonas aeroginosae showed high sensitivity rate to cefotaxim (86.66\%) and low rate of sensitivity (20\%) to ampicillin, Table 7 
Table 6: Antibiotic sensitivity patterns of G-ve isolates .

\begin{tabular}{|c|c|c|c|c|c|}
\hline Type of antibiotic & $\begin{array}{c}\text { Escheri } \\
\text { chia } \\
\text { coli(\%) }\end{array}$ & $\begin{array}{c}\text { K. } \\
\text { pneum } \\
\text { oniae( } \\
\text { \%) }\end{array}$ & $\begin{array}{c}\text { P. } \\
\text { mirabilis( } \\
\mathbf{\%})\end{array}$ & $\begin{array}{c}\boldsymbol{P .} \\
\text { vulgaris( } \\
\mathbf{\%})\end{array}$ & $\begin{array}{c}\boldsymbol{P .} \\
\text { aeruginosa(\%) }\end{array}$ \\
\hline Ciprofloxacin & 79.06 & 59.25 & 77.77 & 100 & 73.33 \\
\hline Ampicillin & 6.97 & 0 & 0 & 71.42 & 20 \\
\hline Tetracycline & 30.23 & 0 & 11.11 & 71.42 & 53.33 \\
\hline Erythromycin & 6.97 & 0 & 0 & 14.28 & 26.66 \\
\hline Tobramycin & 65.11 & 22.22 & 72.22 & 85.71 & 53.33 \\
\hline Gentamicin & 32.55 & 40.74 & 77.77 & 21.42 & 60 \\
\hline Oxacillin & 0 & 0 & 0 & 42.85 & 26.66 \\
\hline Streptomycin & 30.23 & 25.92 & 66.66 & 64.28 & 73.33 \\
\hline Chloramphenicol & 65.11 & 59.25 & 44.44 & 42.85 & 80 \\
\hline Trimethoprim & 18.60 & 48.14 & 27.77 & 71.42 & 26.66 \\
\hline Clindamycin & 4.65 & 22.22 & 16.66 & 57.14 & 40 \\
\hline Lincomycin & 0 & 0 & 0 & 42.85 & 26.66 \\
\hline Ceftazidim & 93.02 & 33.33 & 72.22 & 57.14 & 53.33 \\
\hline Amoxicillin & 11.62 & 22.22 & 27.22 & 85.71 & 46.66 \\
\hline Cephalothin & 23.25 & 14.81 & 44.44 & 71.42 & 33.33 \\
\hline Amikacin & 76.74 & 22.22 & 83.33 & 42.85 & 66.66 \\
\hline Amoxiclave & 81.39 & 81.48 & 88.88 & 85.71 & 53.33 \\
\hline Nitrofurantoin & 81.39 & 70.37 & 77.77 & 92.85 & 73.33 \\
\hline Cefotaxime & 86.04 & 77.77 & 94.44 & 71.42 & 86.66 \\
\hline & & & & & \\
\hline
\end{tabular}




\section{Discussion}

Proper and timely treatment of urinary tract infection in the neonatal period If left untreated, it increases the risk of urosepsis and renal damage. However, mostly specific Non-clinical findings may cause diagnostic difficulties. infants tachypnea,, They may present with severe clinical findings such as cyanosis, lethargy, irritability, or they may be asymptomatic. 9 In premature infants, apnea, tachypnea, bradycardia, hypoxia, lethargy, systemic clinical findings such as abdominal distention, feeding intolerance 2 In some newborns, jaundice is the only sign of urinary infection. 10 In our study, the most common reason for admission was found to be jaundice. This finding Urinary tract infection must be included in the differential diagnosis of unexplained neonatal jaundice. It was important because it showed that it should be considered. Indeed, in the literature with unexplained indirect hyperbilirubinemia after the third postnatal day In a study conducted in newborns, the frequency of urinary tract infection was quite high as $12.5 \%$. $11 \mathrm{In}$ infants younger than 8 weeks with signs of jaundice In another study, urinary infection rate was found to be 7.5\%.10 Nutrition-related findings of urinary system infections in the neonatal period Fuck. Vomiting accounts for 9-41\% of admission complaints and $15-43 \%$ of complaints in different clinical studies. decrease in weight gain, 3-5\% watery stools, 3-5\% nutritional difficulties 12,13 The most common nutritional problems in infants included in our study. The complaints were vomiting and feeding difficulties. Finding of urinary infections with fever It has been reported in term infants at a rate of 20-40\%. 12.13 In addition, all febrile term The frequency of urinary tract infections in newborns is approximately $15 \% .1 \mathrm{In}$ this study, fever, was the complaint of $9.3 \%$ of the patients. The frequency of fever in physical examination was $13.9 \%$. was detected. Urinary analysis is also specific and sensitive. 14 The diagnosis of urinary tract infection is sterile in the neonatal 
period. urine culture obtained by bladder catheterization or suprapubic aspiration is placed. False positive results in the diagnosis of urine culture taken with a bag 1,15 However, in recent years, collections collected with bladder and lumbar stimulation Studies on the safety of midstream urine have been published.16,17 Bladder 10000$50000 \mathrm{CFU} / \mathrm{ml}$ or $10000-50000 \mathrm{CFU} / \mathrm{ml}$ in the presence of pyuria in urine culture taken by catheterization $\geq 50000 \mathrm{CFU} / \mathrm{ml}$ in the absence of pyuria or in culture taken by suprapubic aspiration Growth of a single uropathogenic microorganism $\geq 1000$ $\mathrm{CFU} / \mathrm{ml}$ is required for diagnosis.1,15 $4 \%$ of urinary tract infections in term newborns and infants younger than 3 months While bacteremia accompanies 7 of them, this rate is $13 \%$ in 1,4 preterms. No growth was detected in the blood culture of any of our patients, the number of cases and the term of the cases. associated with newborns. The necessity of lumbar puncture in urinary tract infections is highly controversial. is an issue. Patients with febrile urinary tract infections who appear well in many studies The rate of bacterial meningitis in term newborns was found to be quite low. Especially In recent years, due to the unnecessary performance of a painful and complicated procedure. avoidance and lumbar puncture only in sickappearing term newborns 19,20 In our study, all of the patients were well. Lumbar puncture was not performed on any of the patients because they were apparently term babies, and There was no clinical deterioration in the follow-up. According to the results of our study, the most frequently reproducing microorganism was found in the literature. Consistent with E. Coli (60.46\%), 34.88\% of these patients had varying degrees of Congenital renal anomalies were detected. Especially urinary system anomaly of E. coli presence of a variety of conditions that significantly increase the risk of urinary tract infection. There are virulence factors. The most important of these is the adhesion of bacteria to the uroepithelium. 21. Other gramnegative bacteria except E. coli and rarely Gram-positive bacteria are the causative agents of urinary tract infections in term newborns. 4 Irrespective of the type of causative microorganism, urinary tract In terms of renal and urinary anomalies, all 
newborns diagnosed with infection Evaluation with ultrasonography is recommended. In our study, renal and urinary among the growing microorganism species in terms of the presence of abnormal ultrasound findings. no statistical difference was observed. However, renal ultrasonography findings were normal. It is also known that the presence of vesicoureteral reflux and renal scar does not rule out. 8 In the literature, the frequency of vesicoureteral reflux in urinary tract infections due to E. coli very low, but the majority of vesicoureteral reflux cases are E. Coli It has been found to be detected in urinary infections with microorganisms other than Antibiotic therapy in neonatal urinary tract infections is mostly neonatal Empirical initiation is similar to sepsis. However, in some cases the Hospitalization is based on culture results and antibiotics are selected according to the antibiogram. The first choice in empirical treatment is the combination of ampicillin and aminoglycoside. In nosocomial urinary tract infections, causative microorganisms and antibiotics Treatment decision should be made by taking into account their resistance.23 In our study, Of 36 patients who were started on the combination of ampicillin and gentamicin as empirical therapy. Resistant to both ampicillin and gentamicin of the microorganisms that grew in 11 (30.55\%) according to the antibiogram results of these patients and their treatment is different. It was observed that they continued with antibiotics. Antibiotics of microorganisms by year When their resistances were compared, gentamicin in E. coli and Acinetobacter species. resistance was found to change. This result shows that antibiotic resistance is a dynamic process and that antibiotic preferences are related to intensive care-specific resistance rates and It is quite important in terms of showing that it should be done taking into account the changes. was important. Clinical and laboratory evaluation of urinary tract infections in the neonatal period. findings are variable. Whole blood analysis, complete urinalysis and acute phase reactants urine It is not decisive in the diagnosis and exclusion of urinary tract infection. Pathogen microorganisms and 
their antibiotic susceptibility have changed over the years. can show. Therefore, empirical antibiotic choice has to be socially and intensively .

Conclusion: Neonatal urinary tract infections can be clinically asymptomatic or cause sepsis and renal damage and may be a major cause of morbidity and mortality. The initiation of empirical antibiotic therapy according to variable antibiotic resistance is as important as the clinical and laboratory findings for early and effective treatment.

\section{References}

1- Spencer JD, Schwadere A, McHuge K, Hanis DS. Pediatric urinary tract infections: an analysis of hospitalizations, charge, and costs in the USA. Pediatr Nephrol 2010; 25: 2469-75.

2- Shaikh N, Morone NE, Farrel MH. Prevalence of urinary tract infection in children. A meta- analysis. Pediatr Infect Dis J 2008; 27(4):302-8.

3- Bay AG, Anacleto F. Clinical and laboratory profile of urinary tract infection in children among children at outpatient clinic of a Tertiary Hospital. PIDSPJ 2010; 11(1):10-6.

4- Berk B, Ozgu A, Semih T, Tarkan S. Circumcision: Pros and cons. Indian J Urol 2010; 26:12-5.

5- Rai GK, Uperti HC. Rai SK, Shan KP Shrestha RM. Causative agents of urinary tract infections in children and their antibiotic sensitivity pattern: a hospital based study. Nepal Med Coll J 2008; 10 (2):86-90.

- Wagenlehner F Naber K. Treatment of bacterial urinary tract infections: presence and future. Eur Urol 2006; 49:235-44.

6- Mohammed W, Abu G Anahtar K. Screening test for detection of urinary tract infections: Evolution of urinary leukocytes esterase dipstick test. TAF Prev Med Bull 2008; 7:187-90.

7- Freedman A. Urologic diseases in North America project: trends in resource utilization for urinary tract infection in children. J urol 2005; 173:949-54.

8- Ali EM A, Osman AH. Acute urinary tract infections in children in Khartoum State: pathogens, antimicrobial susceptibility and associated risk factors. Arab Journal of Nephrology and Transplantation 2009; 2(2):11-5. 
9- Al-Momani T. Microbiological study of urinary tract infection in children at Princess Haya Hospital in South of Jordan. MEJFM 2006; 4(2):3-7.

10- Al-Haddad A M. Urinary tract infection among pregnant women in AlMukalla district. Yemen. EMHJ 2005; 11(3): 505-10.

11- Abdulhadi SK, Yashua AH, Uba A. Organisms causing urinary tract infection in pediatric patients at Murtala Muhammad Specialist Hospital, Kano Nigeria. International Journal of Biomedical and Health Sciences 2008; 4(4):165-7.

12- Modarres S, Oskoii NN. Bacterial etiologic agents of urinary tract infections in children in the Islamic Republic of Iran. EMHJ 1997; 3(2):2905.

13- Rehman AU, Jahanzeb M, Siddiqui TS, Idris M. Frequency and clinical presentation of UTI among children of Hazara division. Pakistan J Ayub Med Coll Abbottabab 2008; 20(1): 63-5.

14- Theodoros A, Kanelloponlo S, Salakos C, Spilliopoulou I, Ellina A. Nikolakopoulou N M, et al. First urinary infection in neonate, infants and young children: a comparative study. Pediatric Nephrol 2006; 21:1131-7.

15- $\quad$ Sastre JB1, Aparicio AR, Cotallo GD, Colomer BF, Hernández MC; Grupo de Hospitales Castrillo Urinary tract infection in the newborn: clinical and radio imaging studies. Pediatr Nephrol. 2007;22(10):1735-41.

16- Wallace SS, Zhang W, Mahmood NF et al. Renal Ultrasound for Infants Younger Than 2 Months With a Febrile Urinary Tract Infection. AJR Am J Roentgenol. 2015;205(4):894-8.

17- Arshad M, Seed PC. Urinary tract infections in the infant. Clin Perinatol. 2015;42(1):17-28.

18- Garcia FJ, Nager AL. Jaundice as an early diagnostic sign of urinary tract infection in infancy. Pediatrics. 2002;109(5):846-51.

19- Shahian M1, Rashtian P, Kalani M. Unexplained neonatal jaundice as an early diagnostic sign of urinary tract infection. Int $\mathbf{J}$ Infect Dis. 2012;16(7):487-90

20- Maherzi M, Guignard JP, Torrado A. Urinary tract infection in highrisk newborn infants Pediatrics. 1978;62(4):521-3.

21- Bergström T, Larson H, Lincoln K, Winberg J. Studies of urinary tract infections in infancy and childhood. XII. Eighty consecutive patients with neonatal infection. J Pediatr. 1972;80(5):858-66. 
22- Tzimenatos L, Mahajan P, Dayan PS et al. Pediatric Emergency Care Applied Research Network (PECARN). Accuracy of the Urinalysis for Urinary Tract Infections in Febrile Infants 60 Days and Younger. Pediatrics. 2018;141(2). pii: e20173068.

23- Downs SM. Technical report: urinary tract infections in febrile infants and young children. The Urinary Tract Subcommittee of the American Academy of Pediatrics Committee on Quality Improvement. Pediatrics. 1999;103(4):e54.

24- Herreros Fernández ML, González Merino N, Tagarro García A et al. A new technique for fast and safe collection of urine in newborns. Arch Dis Child. 2013 Jan;98(1):27-9.

25- Downey LC, Benjamin DK Jr, Clark RH et al. Urinary tract infection concordance with positive blood and cerebrospinal fluid cultures in the neonatal intensive care unit. J Perinatol. 2013;33(4):302-6. 